\title{
Real-life long-term omalizumab therapy in children with severe allergic asthma
}

\author{
To the Editor:
}

We previously reported the French real-life experience of 1 year of add-on treatment with omalizumab in 101 severe allergic asthmatic children (6-18 years), 92 of whom were still receiving the treatment at the end of the first year [1]. The study provided complementary data to the previous randomised trials [2-6]. We showed a marked drop of $72 \%$ in the mean rate of severe exacerbations (from 4.4 per patient during the preceding year to 1.25 during the year of treatment) and of $88.5 \%$ for hospitalisations ( $44 \%$ of the patients during the preceding year to $6.7 \%$ during the year of treatment); a large improvement in asthma control (from $0 \%$ at initiation to $67 \%$ of well-controlled patients after 1 year); a decrease of $30 \%$ of the mean inhaled corticosteroid (ICS) dose (from 703 at initiation to $488 \mu \mathrm{g}$ fluticasone equivalent per day after 1 year); and a forced expiratory volume in $1 \mathrm{~s}$ (FEV1) increase, from a mean of $88 \%$ to $92.1 \%$ of the predicted value. Treatment was discontinued in six patients due to serious adverse events attributed to omalizumab by the practitioner. Here we report the outcome of this cohort after 2 years of omalizumab treatment.

Outcome was assessed with the same criteria: rate of severe exacerbations, defined by requirement for systemic steroid bursts ( $>2$ days) or hospitalisation; control, according to Global Initiative for Asthma (GINA) guidelines (apart from exacerbations), classified as uncontrolled, partially controlled or well controlled; ICS dose ( $\mu$ g fluticasone equivalent per day); and lung function (FEV1 and forced expiratory flow at $25-75 \%$ of forced vital capacity ( $\mathrm{FEF}_{25-75 \%)}$, both expressed as a percentage of the predicted value). Data are presented as frequencies and percentages for qualitative variables and as mean and $95 \%$ confidence interval for quantitative variables. Comparisons across the visits were performed by McNemar's test for qualitative variables and by $\mathrm{t}$-test for paired samples for quantitative variables. A p-value $<0.05$ was considered significant. All analyses were achieved with SAS software version 9.3 (SAS Institute Inc., Cary, NC, USA).

$73(79.3 \%)$ of the 92 children under treatment at the end of the first year were still receiving the treatment 2 years after initiation and were included in the analysis. Treatment was discontinued in 15 patients during the second year: four because of lack of health improvement, eight because of adverse events attributed to omalizumab, and three for personal reasons unrelated to the treatment. Four patients were lost to follow-up. The eight adverse events are displayed in table 1. Fatigue was reported in six patients and associated with erythema in one, local reactions in another, and an unexpected weight gain in a girl already overweight. General signs occurred in two patients and consisted of abdominal pain, headache and fever in one and haematuria, haemoptysis and arthralgia in the second, both resolved after discontinuing the drug.

At the end of the second year of treatment, we observed the maintenance of the benefits reported at 1 year in the children still receiving omalizumab. The severe exacerbation rate continued to decrease, reaching a mean $(95 \% \mathrm{CI})$ of $0.22(0.03-0.41)$ per year, $-83 \%$ of the rate observed during the first year $(\mathrm{p}=0.0001)$ (fig. 1). No hospitalisation for exacerbation was recorded. We observed a nonsignificant improvement in the level of control, with $80 \%$ well-controlled, $15 \%$ partially controlled and $5 \%$ uncontrolled patients $(\mathrm{p}=0.17)$. At the end of the second year, the mean $(95 \% \mathrm{CI})$ daily ICS dose remained unchanged at 429 (350-509) $\mu \mathrm{g}$ per day $(\mathrm{p}=1)$. No patient discontinued ICS treatment. However, $45(63 \%)$ patients benefited from at least a $50 \%$ decrease in the initial dose of ICS. No additional gain in lung function was seen. At the end of 2 years of treatment, the FEV1 was $89.9 \%$ predicted (95\% CI 86.7-93.0\%) ( $\mathrm{p}=0.38$ ) and the FEF25-75\% was $71.9 \%$ predicted (95\% CI 65.7-78.0\%) ( $\mathrm{p}=0.98)$.

To the best of our knowledge, there are no specific paediatric data on omalizumab effectiveness beyond 1 year of administration. One adult study by PACE et al. [7] reported a marked improvement in clinical parameters and lung function in seven severe asthmatic patients after a 7-year course of omalizumab. In our study, we observed a persistent positive effect on the severe exacerbation rate, and a modest effect on asthma control in the children who continued omalizumab as add-on therapy. The lack of further lung function improvement despite a moderate to high ICS dose raises various hypotheses. The first is the compliance to treatment, which cannot be substantiated in our study as it was not formally evaluated. A second hypothesis is, as previously demonstrated, that FEV1 might not improve further in children with severe asthma [8]. However, modest improvement in FEV1 has been previously reported in clinical trials [6]. In our cohort, 


\begin{tabular}{|c|c|c|c|c|c|c|c|c|}
\hline 2 & $M$ & $\begin{array}{l}11 \text { years } \\
4 \text { months }\end{array}$ & 35 & 1797 & 22 & $\begin{array}{l}375 \mathrm{mg} \mathrm{per} \\
2 \text { weeks }\end{array}$ & Fatigue & $\begin{array}{c}\text { Resolution, } \\
\text { treatment } \\
\text { reintroduced } \\
7 \text { months later }\end{array}$ \\
\hline 3 & M & $\begin{array}{l}15 \text { years } \\
9 \text { months }\end{array}$ & 80 & 572 & 13 & $\begin{array}{l}375 \mathrm{mg} \text { per } \\
2 \text { weeks }\end{array}$ & Fatigue & Resolution \\
\hline 4 & $\mathrm{~F}$ & $\begin{array}{l}17 \text { years } \\
7 \text { months }\end{array}$ & 51 & 1796 & 23 & $\begin{array}{l}375 \text { mg per } \\
2 \text { weeks }\end{array}$ & $\begin{array}{l}\text { Fatigue, local } \\
\text { reaction }\end{array}$ & Resolution \\
\hline 5 & M & $\begin{array}{l}15 \text { years } \\
8 \text { months }\end{array}$ & 82 & 139 & 18 & $\begin{array}{l}300 \mathrm{mg} \text { per } \\
4 \text { weeks }\end{array}$ & Fatigue, erythema & Resolution \\
\hline 8 & M & $\begin{array}{l}11 \text { years } \\
3 \text { months }\end{array}$ & 60 & 101 & 14 & $\begin{array}{l}300 \mathrm{mg} \mathrm{per} \\
4 \text { weeks }\end{array}$ & $\begin{array}{l}\text { Haematuria, } \\
\text { haemoptysis, } \\
\text { arthralgia }\end{array}$ & Resolution \\
\hline
\end{tabular}

F: female; M: male. ${ }^{\#}$ : at the initiation of the treatment.

FEV1 was stabilised at around $90 \%$ predicted, close to the expected value in controlled children, and this might be related to the disappearance of severe exacerbations [9].

Another main finding in our study is the high rate $20.7 \%)$ of omalizumab cessation during the second year. Besides treatment failure, patients' own decisions and loss to follow-up, $8 \%$ of the patients stopped omalizumab because of side-effects, $75 \%$ of which were fatigue following injection. This was already reported during the first year of treatment but has not been reported in other studies $[2-5,10]$. Two patients experienced generalised signs related to omalizumab, as they did not exist before initiating and disappeared after discontinuing the treatment (table 1) [10]. Although treatment has been reintroduced with success in one patient, these notifications warrant a careful long-term follow-up of treated children as delayed side-effects can happen. However, the whole benefit/risk ratio observed in this cohort favours the use of add-on treatment with omalizumab in severe allergic asthmatic children resistant to high-dose ICS as recently defined in the European Respiratory Society/American Thoracic Society Task Force [11] and GINA guidelines [12].

While the rationale for long-term treatment is supported by the pharmacokinetic-pharmacodynamic model described by LOWE and RENARD [13], the duration of omalizumab treatment is still under discussion. Our

FIGURE 1 Change in exacerbation rates over a period of 104 weeks with add-on omalizumab treatment in children with uncontrolled severe allergic asthma. Data are presented as means with $95 \%$ confidence intervals.

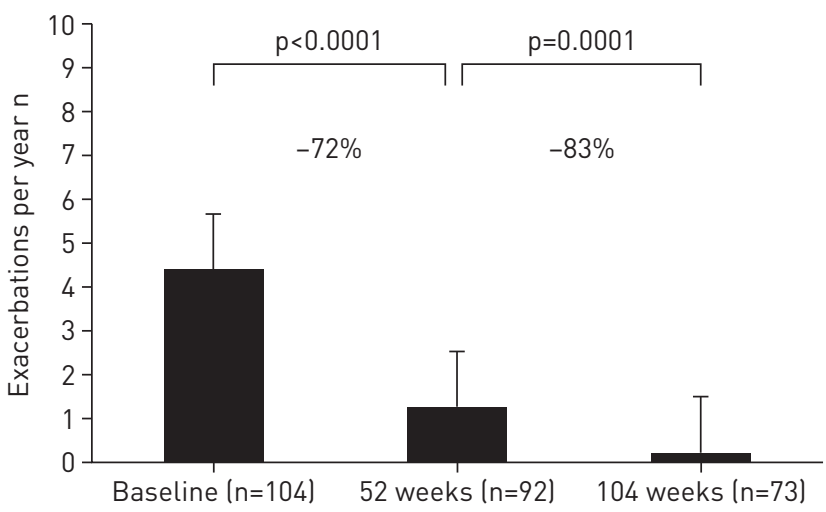


real-life study suggests that omalizumab should be continued for $>1$ year. This is in accordance with the report of MOLIMARD et al. [14], who analysed asthma control in 61 French patients (including 14 children) after discontinuation of omalizumab. Control was maintained for at least 6 months in $45 \%$ of the patients overall and $57 \%$ of the children. A treatment of longer than 3.5 years was associated with no loss of control during the following 6 months. Recently, the XPORT study evaluated the persistency of response to omalizumab in 176 adults with moderate to severe allergic asthma after long-term treatment ( $\geqslant 5$ years) [15]. Patients were randomised to continuation of omalizumab or withdrawal to placebo. At 1 year, $67 \%$ of the treated patients remained without exacerbation, compared with $47.7 \%$ in the placebo group.

All in all, the impact of omalizumab treatment on the natural history of severe asthma in children deserves to be further examined by long-term studies to define both the criteria and the timing for discontinuing the treatment. Adverse events should be carefully monitored and reported to pharmacovigilance units, with the aim of enhancing the knowledge of long-term omalizumab safety.

0 @ERSpublications

Beneficial effects at 2 years of omalizumab on severe exacerbations and control in severe allergic asthmatic children http://ow.ly/LGgnw

Antoine Deschildre ${ }^{1}$, Christophe Marguet ${ }^{2}$, Carole Langlois ${ }^{3}$, Isabelle Pin ${ }^{4}$, Jean-Luc Rittié ${ }^{5}$, Jocelyne Derelle ${ }^{6}$, Rola Abou Taam ${ }^{7}$, Michael Fayon ${ }^{8}$, Jacques Brouard ${ }^{9}$, Jean Christophe Dubus ${ }^{10}$, Daniel Siret ${ }^{11}$, Laurence Weiss ${ }^{12}$, Guillaume Pouessel $^{13}$, Laurent Beghin ${ }^{14}$ and Jocelyne Just ${ }^{15,16,17}$

${ }^{1}$ Unité de pneumologie et allergologie pédiatriques, pôle enfant, clinique de pédiatrie Jeanne de Flandre, CHRU de Lille, Université Nord de France, Lille, France. ${ }^{2}$ Pediatric respiratory disease and allergy unit, University Charles Nicolle Hospital, EA3830 GHRV, Rouen University, Rouen, France. ${ }^{3}$ Département de biostatistiques, CHRU de Lille, Université Nord de France, Lille, France. ${ }^{4}$ Pédiatrie, Pôle Couple Enfants, CHU de Grenoble, INSERM U823, Institut Albert Bonniot, Université Joseph Fourier, Grenoble, France. ${ }^{5}$ Allergologie - Pneumologie, Hôpital des Enfants, CHU Purpan Toulouse, Toulouse, France. ${ }^{6}$ Service de pédiatrie 1, Hôpital d'enfants de Brabois, CHU Nancy, Vandoeuvre-Lés-Nancy, France. ${ }^{7}$ Service de pneumologie et d'allergologie pédiatriques, hôpital Necker-Enfants-Malades, Paris, France. ${ }^{8} \mathrm{CHU}$ de Bordeaux, Département de Pédiatrie, Centre d'Investigation Clinique (CIC 0005), Bordeaux, France. ${ }^{9} \mathrm{CHU}$ de Caen, Dept of Pediatrics, Research unit EA 4655 U2RM, Caen, France. ${ }^{10}$ Unité de pneumologie et médecine infantile, CNRS, URMITE 6236, CHU Timone-Enfants, Aix-Marseille Université, Marseille, France. ${ }^{11}$ Service de Pédiatrie, CH de SaintNazaire, Saint-Nazaire, France. ${ }^{12}$ Pôle médico-chirurgical de Pédiatrie, CHU de Hautepierre, Strasbourg, France. ${ }^{13}$ Service de pediatrie, CH Roubaix, Roubaix, France. ${ }^{14} \mathrm{CIC}-9301-$ Inserm-CHU (Centre d'Investigation Clinique de Lille), CHRU de Lille and U995 Inserm, and Université Nord de France, Lille, France. ${ }^{15}$ Centre de l'Asthme et des Allergies, Hôpital d'Enfants Armand-Trousseau, Paris, France. ${ }^{16}$ INSERM, UMR_S 1136, Sorbonne Universités, UPMC Université Paris 06, Paris, France. ${ }^{17}$ Institut Pierre Louis d’Epidémiologie et de Santé Publique, Equipe EPAR, Paris, France.

Correspondence: Antoine Deschildre, Unité de pneumologie-allergologie pédiatrique, Clinique de pédiatrie Jeanne de Flandre, CHRU, 59037 Lille cedex, France. E-mail: antoine.deschildre@chru-lille.fr

Received: Jan 172015 | Accepted after revision: March 222015 | First published online: May 282015

Conflict of interest: Disclosures can be found alongside the online version of this article at erj.ersjournals.com

Support statement: This survey was funded by a grant from Novartis France and supported by the French Pediatric Pulmonology and Allergy Society (SP2A). Funding information for this article has been deposited with FundRef.

Acknowledgements: We are grateful to Céline Clairet (Centre d'Investigations Cliniques Pédiatriques, Lille University Hospital, Lille, France) for data collection and management.

\section{References}

1 Deschildre A, Marguet C, Salleron J, et al. Add-on omalizumab in children with severe allergic asthma: a 1-year real life survey. Eur Respir J 2013; 42: 1224-1233.

2 Lanier B, Bridges T, Kulus M, et al. Omalizumab for the treatment of exacerbations in children with inadequately controlled allergic (IgE-mediated) asthma. J Allergy Clin Immunol 2009; 124: 1210-1216.

3 Milgrom H, Berger W, Nayak A, et al. Treatment of childhood asthma with anti-immunoglobulin E antibody (omalizumab). Pediatrics 2001; 108: E36.

4 Kulus M, Hebert J, Garcia E, et al. Omalizumab in children with inadequately controlled severe allergic (IgE-mediated) asthma. Curr Med Res Opin 2010; 26: 1285-1293.

5 Busse WW, Morgan WJ, Gergen PJ, et al. Randomized trial of omalizumab (anti-IgE) for asthma in inner-city children. N Engl J Med 2011; 364: 1005-1015.

6 Normansell R, Walker S, Milan SJ, et al. Omalizumab for asthma in adults and children. Cochrane Database Syst Rev 2014; 1: CD003559.

7 Pace E, Ferraro M, Bruno A, et al. Clinical benefits of 7 years of treatment with omalizumab in severe uncontrolled asthmatics. J Asthma 2011; 48: 387-392.

8 Lødrup Carlsen KC, Mowinckel P, Hovland V, et al. Lung function trajectories from birth through puberty reflect asthma phenotypes with allergic comorbidity. J Allergy Clin Immunol 2014; 134: 917-923.

9 O'Byrne PM, Pedersen S, Lamm CJ, et al. Severe exacerbations and decline in lung function in asthma. Am J Respir Crit Care Med 2009; 179: 19-24. 
10 Milgrom H, Fowler-Taylor A, Vidaurre CF, et al. Safety and tolerability of omalizumab in children with allergic (IgE-mediated) asthma. Curr Med Res Opin 2011; 27: 163-169.

11 Chung KF, Wenzel SE, Brozek JL, et al. International ERS/ATS guidelines on definition, evaluation and treatment of severe asthma. Eur Respir J 2014; 43: 343-373.

12 Global Initiative for Asthma. Global Strategy for Asthma Management and Prevention. 2014. www.ginasthma.org

13 Lowe PJ, Renard D. Omalizumab decreases IgE production in patients with allergic (IgE-mediated) asthma; PKPD analysis of a biomarker, total IgE. Br J Clin Pharmacol 2011; 72: 306-320.

14 Molimard M, Mala L, Bourdeix I, et al. Observational study in severe asthmatic patients after discontinuation of omalizumab for good asthma control. Respir Med 2014; 108: 571-576.

15 Busse WW, Trzaskoma B, Omachi TA, et al. Evaluating Xolair persistency of response after long-term therapy (XPORT). Am J Respir Crit Care Med 2014; 189: A6576.

\section{Bronchial thermoplasty in asthma: 2-year follow-up using optical coherence tomography}

To the Editor:

Bronchial thermoplasty (BT) is a novel, nonpharmacological procedure for treatment of severe asthma. Recently, the Asthma Intervention Research 2 clinical trial demonstrated asthmatics had fewer hospitalisations following BT, which persisted 5 years after therapy [1]. However, it is well recognised that asthma is a heterogeneous disease with distinct asthma phenotypes and, not surprisingly, not all asthmatics in that trial benefited from BT [2].

Although bronchoscopic biopsies, pulmonary function tests, exhaled nitric oxide, sputum eosinophil counts and other biological measures have been proposed as biomarkers for evaluating treatment effects [3], these biomarkers cannot provide regional information to characterise airway remodelling in the targeted airways prior to and longitudinally following treatment. Although imaging approaches, such as computed tomography of the lung [4] and magnetic resonance imaging using inhaled contrast agents [5], do provide regional information, these tests are limited to indirect assessment of the small airways. Optical coherence tomography $(\mathrm{OCT})$ is a minimally invasive imaging technique for visualising airway wall structures with near-histological resolution [6-8]. OCT has been used for the evaluation of airway remodelling $[9,10]$ and early lung neoplastic changes $[8,11]$.

Identifying asthma phenotypes with the greatest response to BT is likely to bring the potential for better patient selection and ultimately better patient outcomes, and further research into methods capable of careful patient selection for BT has been strongly recommended [12]. Here, our objective was to provide a pilot study in two asthma patients who underwent BT in order to investigate the role of OCT imaging for evaluating airway remodelling prior to and longitudinally following BT treatment.

Two patients with chronic persistent asthma provided written informed consent. Flexible bronchoscopy was performed under local anaesthesia and conscious sedation [7]; BT was performed according to established protocols (Boston Scientific Corp., Marlborough, MA, USA) [2, 13]. OCT images of the subsegmental branch of the right-lower lobe (RB8a\&b and RB9a\&b) were acquired prior to and immediately after BT as well as at 3 weeks, 6 weeks, 6 months and 2 years post-BT using a custom-built swept-source OCT system [14] and a C7 Dragonfly Imaging Catheter (St Jude Medical Inc., St Paul, MN, USA). OCT airway segments matched by visual inspection at each time-point were selected for analysis. The lumen area $\left(A_{\mathrm{i}}\right)$ and outer wall area $\left(A_{\mathrm{o}}\right)$ for three consecutive OCT slices were manually segmented (ImageJ; National Institutes of Health, Bethesda, MD, USA) to generate airway wall (WA) percentage:

$$
\mathrm{WA}=\frac{A_{\mathrm{i}}}{A_{\mathrm{o}}} \times 100
$$

Patient A was a 51-year-old male with no smoking history and an asthma duration of 6 years. Patient B was a 56-year-old female and an ex-smoker at the time of the study (10 pack-years) with an asthma 